\title{
Awareness of Childhood Caries Among Parents in Andhra Pradesh
}

\author{
Allour Vaishnavi', Dhanraj Ganapathy ${ }^{2}$ and L. Keerthi Sasanka ${ }^{3}$ \\ ${ }^{1}$ Saveetha Dental College and Hospitals, Saveetha Institute of Medical \\ and Technical Sciences, Saveetha University, Chennai, India. \\ ${ }^{2}$ Professor and Head, Department of Prosthodontics, Saveetha Dental College and Hospitals, Saveetha \\ Institute Of Medical and Technical Sciences, Saveetha University, Chennai 77 ,India. \\ ${ }^{3}$ Senior Lecturer, Department of Prosthodontics, Saveetha Dental College and Hospitals, Saveetha \\ Institute Of Medical and Technical Sciences, Saveetha University, Chennai 77 ,India.
}

\section{ABSTRACT}

Dental caries is the most common chronic disease of childhood, globally. Although dental caries' levels have been declining the world over, the problem of early childhood caries (ECCs) has remained unchanged in many areas of the world, especially the socially deprived.The survey is conducted among Parents in Andhra Pradesh. Self-structured questionnaires were prepared and circulated through an online portal, then the data collected, and results were tabulated. The results were collected and then analyzed through SPSS software. Descriptive statistical analysis was carried out and the chisquare test was used and the p-value was calculated.It was found that the parents knew that oral hygiene was important to general health but was unable to follow optimal oral hygiene practices. The reason for such poor maintenance and practice could be due to low educational low levels of awareness on oral hygiene practices, low economic status of the participants.There was a general lack of knowledge on methods of oral health maintenance even though the participants acknowledged that oral health was vital to general wellbeing. Routine dental camps should be conducted with clinicians demonstrating oral hygiene practices and performing check-ups

KEY WORDS: CHILDHOOD, CARIES, ORAL HYGIENE, FLUORIDE.

\section{INTRODUCTION}

Dental caries is the most common chronic disease of childhood, globally.(Silk et al., 2012) Although dental caries' levels have been declining the world over, the problem of early childhood caries (ECCs) has remained unchanged in many areas of the world, especially the socially deprived.(Bedi, Lewsey and Gilthorpe, 2000)

\section{ARTICLE INFORMATION}

*Corresponding Author: dhanarajmganapathy@yahoo.co.in Received 10th June 2020 Accepted after revision 12th August 2020 Print ISSN: 0974-6455 Online ISSN: 2321-4007 CODEN: BBRCBA

Thomson Reuters ISI Web of Science Clarivate Analytics USA and Crossref Indexed Journal

\section{Clarivate
Analytics}

NAAS Journal Score 2020 (4.31) SJIF: 2020 (7.728)

A Society of Science and Nature Publication,

Bhopal India 2020. All rights reserved.

Online Contents Available at: http//www.bbrc.in/

Doi: http://dx.doi.org/10.21786/bbrc/13.7/100
Dental caries affecting the primary dentition of preschool children are referred to as ECCs. ECC can be defined as "the presence of one or several decayed (non cavitated or cavitated lesions), missing (due to caries), or filled tooth surfaces in any primary tooth in a child under the age of six years."(Williams, Whittle and Gatrell, 2002; American Academy of Pediatric Dentistry, American Academy of Pediatrics and American Academy of Pediatric Dentistry Council on Clinical Affairs, 2005) .

ECCs is a multifactorial disease with an etiology that involves a complex interaction between biological and socioeconomic factors. It is classified as mild, moderate, and severe. In children younger than 3 years of age, any sign of smooth-surface caries is indicative of severe ECCs (S-ECCs). From ages 3 through 5 years, 1 or more cavitated, missing (due to caries), or filled smooth surfaces 
in primary maxillary anterior teeth or a decayed, missing, or filled score of $\geq 4$ (age 3 ), $\geq 5$ (age 4 ), or $\geq 6$ (age 5) surfaces denote S-ECC.

ECC affects the deciduous dentition more commonly referred to as "milk" teeth. Deciduous teeth are very inappropriately referred to as "temporary teeth" when in reality they are responsible for general health, mastication, phonetics, esthetics, and self-esteem, and also psychological comfort. Deciduous teeth are an integral part of oral, general health, and affect the quality of life.(Sheiham, 2005) Deciduous teeth if infected by dental caries can cause pain and disfigurement making children uncooperative for extensive treatment, sometimes culminating the use of general anesthesia (GA). Treatment under GA in children is not without its associated risks. In addition, very few dentists are willing to do treatment in such young children due to its time-consuming nature, monetary returns and are not trained enough.(Almeida et al., 2000) (Tate et al., 2002)(Halawany et al., 2018).

Deciduous teeth and permanent teeth are explicitly related, and infection from deciduous teeth can directly pass on to permanent teeth. To maintain the permanent teeth uninfected, dental practitioners advise pulp therapy or extraction and many parents choose to get deciduous teeth extracted due to financial and time constraints. (Andreasen, Andreasen and Andersson, 2018)Deciduous teeth are also the "best natural space maintainer." Parents have responsibility for their child's oral health care. Preschool children are not capable of brushing themselves and lack the manual dexterity and the psychological maturity to understand the importance of maintaining oral health. (Wright and Kennedy, 1978) With changing lifestyles, a trend of having a single child, and increased cost of living, most of the parents are working with very little time left for performing day-to-day oral health care practices in their child's early years. Especially in preschool children, parental role is the most important aspect of maintaining good oral health.(Castilho et al., 2013)

Parents are role models for their children. Children learn habits by imitating their role models and the best way to teach them is to practice these oral hygiene practices ourselves. Dental caries is a preventable condition and if it is noticed at an early stage, children cooperate better and parents save their valuable time and money spent on dental treatments which are also inclusive of the loss of pay for multiple visits for the treatment. Hence, prevention at the root level, i.e., primordial prevention and oral health education of parents is essential as the preschool age group (2-4 years of age) is dependent on them for their oral health care needs. Later, from 2 years onward, oral health promotion strategies such as fluoridated toothpaste, etc., can be begun in cooperation with the parents. To attain these goals, one needs to assess the existing levels of knowledge, attitude, and practices bringing about the necessary changes. (Sankeshwari et al., 2012)

\section{MATERIAL AND METHODS}

This is a survey type study setting. This survey is taken among random parents of Andhra Pradesh. The sample size of this study is 100 participants. Parents are mainly included in this study. Search engines used in this study are PubMed and Elsevier accordingly. The self-structured questionnaire (mentioned below) of 10 questions has been prepared and circulated through an online survey portal link among the participants. The results were collected and then analyzed through SPSS software. Descriptive statistical analysis was carried out and the chi-square test was used and the p-value was calculated.(Sen et al., 2017; Duraisamy et al., 2019)(Ganapathy et al., 2016) (Jain, Ranganathan and Ganapathy, 2017)(Ashok and Suvitha, 2016)(Ajay et al., 2017).

\section{Questionnaire}

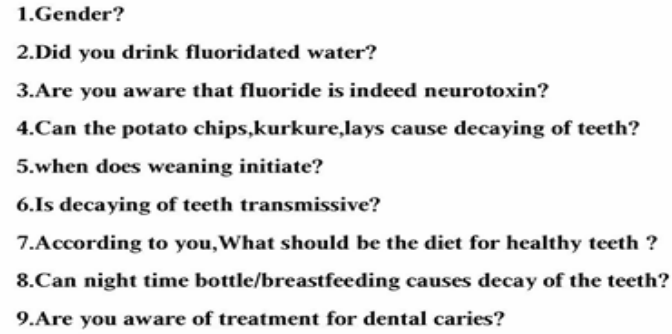

Figure 1: Pie chart represents that $49 \%$ are females (red) and $51 \%$ are males(blue) who participated in the survey.

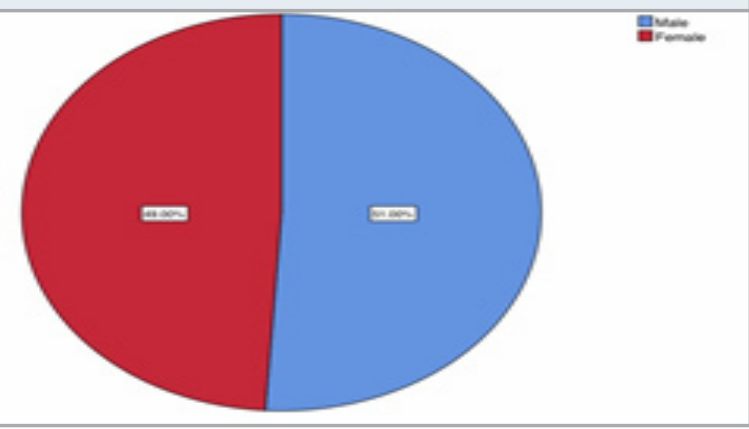

Figure 2: Pie chart represents that $69 \%$ of the participants are aware that they are consuming fluoridated water (blue), 31\% of them responded that they are not consuming fluoridated water. (red)

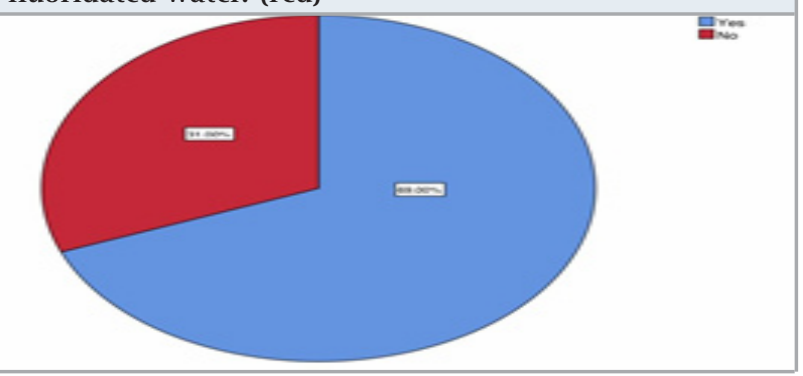


Figure 3: Pie chart represents that 75\% (blue)of participants are aware that fluoride is indeed neurotoxin and $4 \%$ (red) of them are unaware.

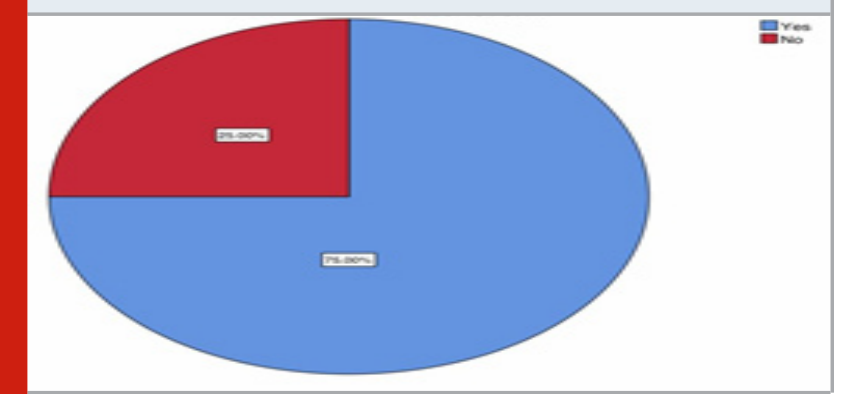

Figure 4: Pie chart represents that 75\%(blue) of participants are aware that consumption of potato chips, kurkure, lays cause decaying of the teeth and 25\%(red) of the participants responded that these can not be the reason for decaying teeth.

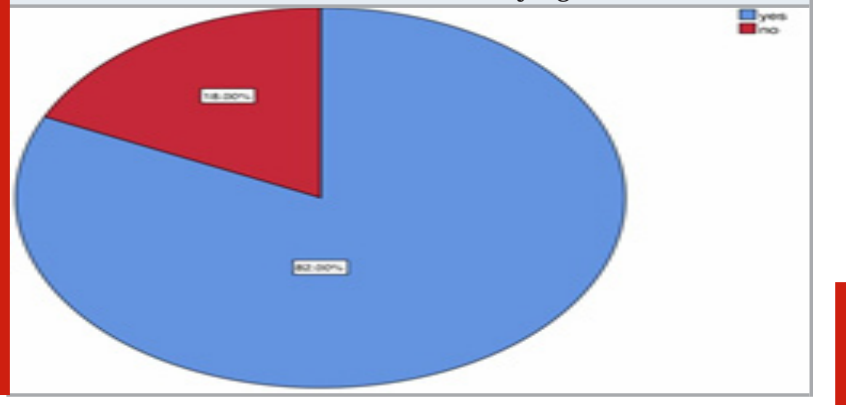

Figure 5: Pie chart represents that $44 \%$ (blue) of the participants responded that weaning initiates in infants, 33\% (red) responded that weaning initiates at less than 5 years of age, $17 \%$ (green) of them answered that weaning initiates at 5 years of age and $6 \%$ (orange) of them responded that weaning initiates at 10 years of age.

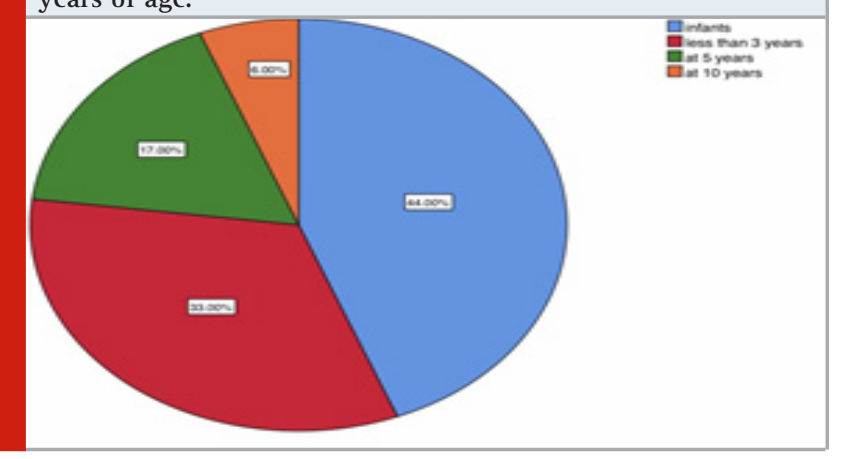

RESULTS AND DISCUSSION

The results of this survey, as per responses for the questionnaire collected from the participants. It was found that the parents knew that oral hygiene was important to general health but was unable to follow optimal oral hygiene practices. The reason for such poor maintenance and practice could be due to low educational low levels of awareness on oral hygiene practices, low economic status of the participants.FIGURE $149 \%$ are females and $51 \%$ are males participated in the survey.FIGURE 2 69\% of the participants answered that they are consuming fluoridated water and 31\% of them responded that they are not consuming fluoridated water.FIGURE 3 75\% of participants answered that they are aware of fluoride is indeed neurotoxin and 24\% of them are unaware.FIGURE $475 \%$ of participants answered that consumption of potato chips, kurkure, lays cause decaying of the teeth and 25\% of the participants responded that these can not be the reason for decaying teeth.

FIGURE $544 \%$ of the participants responded that weaning initiates in infants, 33\% responded that weaning initiates at less than 5 years of age, $17 \%$ of them answered that weaning initiates at 5 years of age and $6 \%$ of them responded that weaning initiates at 10 years of age.FIGURE 6 66\% of the participants responded that decaying of teeth is transmissive and $34 \%$ of them answered that decaying is not transmissive. FIGURE $722 \%$ of the participants answered that protein-rich diet can be healthy for the teeth, $6 \%$ of them responded that fat-rich diet is healthy, $8 \%$ of them answered that carbohydrate-rich diet can be healthy for the teeth and 64\% of them answered that all these are required for the healthy teeth.FIGURE $872 \%$ of the participants answered that night time bottle-feeding or breastfeeding can cause decay of the teeth and $28 \%$ of them responded that it cannot be the reason for decaying of the teeth.

Figure 6: Pie chart represents that $66 \%$ (blue)of the participants responded that decaying of teeth is transmissive and 34\% (red) of them answered that decaying is not transmissive.

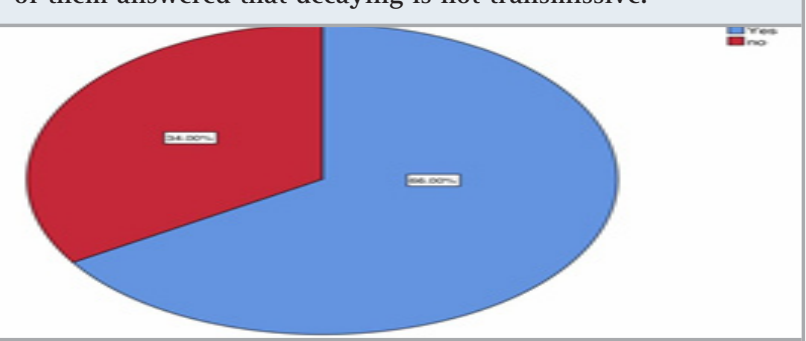

Figure 7: Pie chart represents that 22\% (blue)of the participants answered that protein-rich diet can be healthy for the teeth, $6 \%(\mathrm{red})$ of them responded that fat-rich diet is healthy, 8\%(green) of them answered that carbohydrate-rich diet can be healthy for the teeth and 64\%(orange) of them answered that all these are required for the healthy teeth.

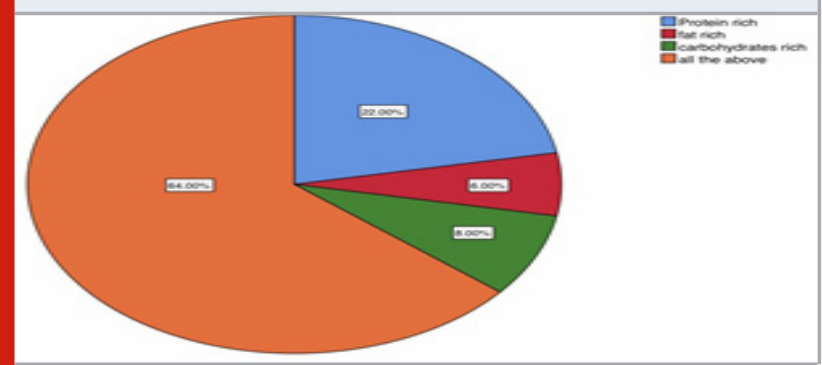

FIGURE 9 82\% of the participants responded that they are aware of treatment for dental caries and 18\% of them are unaware.FIGURE 10 The association between gender and healthy teeth by adding nutrients in the diet.X axis represents genders and Y-axis represents 
the number of participants who responded to different dietary food for healthy teeth. Chi-square test was done and the association found to be statistically significant. Pearson's chi-square test showing $\mathrm{p}=0.001 .(<0.05)$ hence statistically significant, proving females have better knowledge about diet healthy teeth than males. FIGURE 11 The association between gender and weaning age.Xaxis represents genders and Y-axis represents the number of participants who responded to the age for weaning. Chi-square test was done and the association found to be statistically significant.

Figure 8: Pie chart represents that $72 \%$ (blue) of the participants are aware that night time bottle-feeding or breastfeeding can cause decay of the teeth and $28 \%$ (red)of them responded that it cannot be the reason for decaying of the teeth.

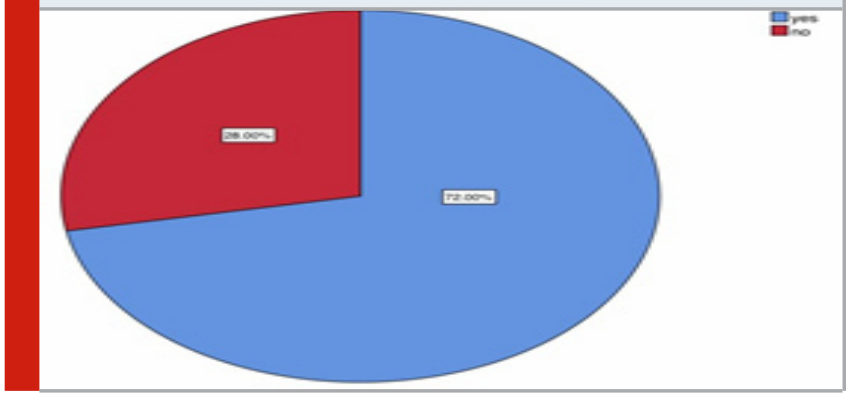

Figure 9: Pie chart represents that $82 \%$ (blue) of the participants responded that they are aware of treatment for dental caries and $18 \%$ (red)of them are unaware.
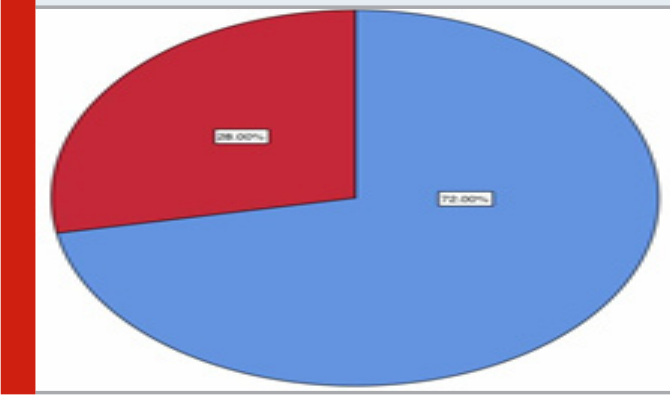

븡

Pearson's chi-square test showing $\mathrm{p}=0.03(<0.05)$ hence statistically significant, proving males have better knowledge than females. FIGURE 12 The association between gender and consumption of fluoridated water.X axis represents genders and the Y-axis represents the number of participants who responded Whether consuming or not. Chi-square test was done and the association found to be statistically significant. Pearson's chi-square test showing $\mathrm{p}=0.005 .(<0.05)$ hence statistically significant, proving males have consumed more fluoridated water than females.FIGURE 13 The association between gender and consuming junk foods can cause decaying of teeth.X-axis represents genders and $\mathrm{Y}$-axis represents the number of participants who responded whether junk foods cause decaying of the tooth or not. Chi-square test was done and the association found to be statistically significant.

Pearson's chi-square test showing $\mathrm{p}=0.01 .(<0.05)$ hence statistically significant, proving males have better knowledge than females. FIGURE 14 The association between gender and awareness of treatment for dental caries.X axis represents genders and Y-axis represents the number of participants who responded aware and unaware. Chi-square test was done and the association found to be statistically significant. Pearson's chisquare test showing $\mathrm{p}=0.006 .(>0.05)$ hence statistically significant, proving males have better awareness than females.

Figure 10: Bar graph represents the association between gender and healthy teeth by adding nutrients in the diet.X axis represents genders and Y-axis represents the number of participants who responded to different dietary food for healthy teeth. Chi-square test was done and the association found to be statistically significant. Pearson's chi-square test showing $\mathrm{p}=0.001 .(<0.05)$ hence statistically significant, proving females have better knowledge about diet and healthy teeth than males. Blue represents protein-rich, red represents fat-rich, green represents carbohydrate-rich and orange represents all these nutrients in the diet.

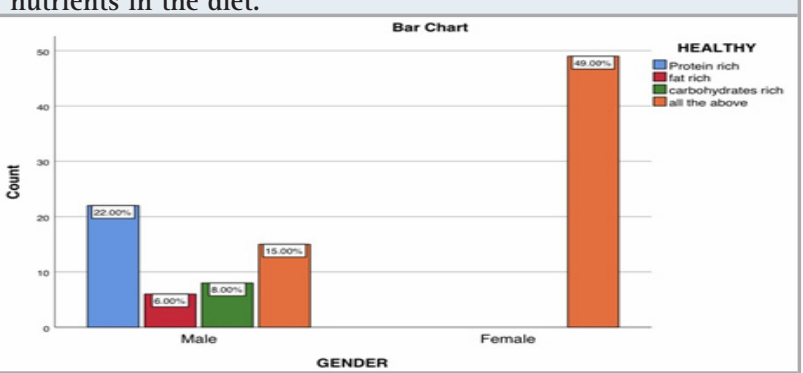

Figure 11: Bar graph represents the association between gender and weaning age. $\mathrm{X}$-axis represents genders and $\mathrm{Y}$-axis represents the number of participants who responded to the age for weaning. A Chi-square test was done and the association found to be statistically significant. Pearson's chi-square test showing $\mathrm{p}=0.03(<0.05)$ hence statistically significant, proving males have better knowledge than females. Blue represents infants, red represents less than 3 years, green represents at 5 years and orange represents at 10 years.

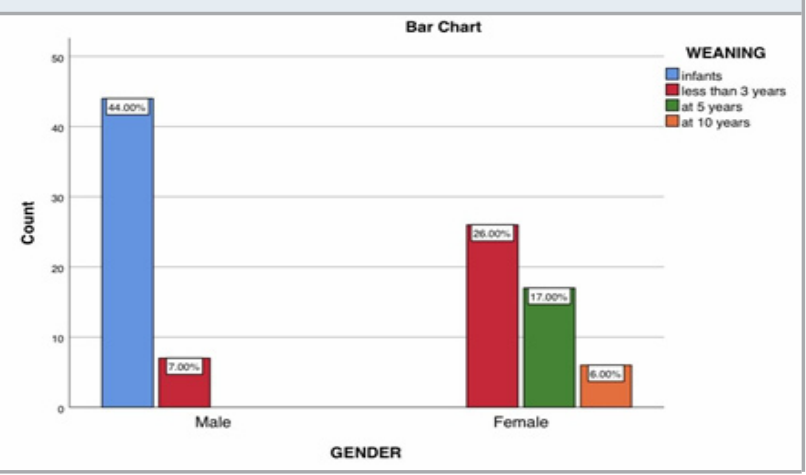

In addition, children with primary dentition affected by dental caries are prone to the development of dental caries in permanent dentition. Hence, children reinforced at an early age by their parents are motivated and trained for a lifetime.(Ariga et al., 2018)(Jyothi et al., 2017) (Selvan and Ganapathy, 2016)(Subasree, Murthykumar and Dhanraj, 2016)(Vijayalakshmi and Ganapathy, 2016) (Ganapathy, Kannan and Venugopalan, 2017)(Ashok 
et al., 2014)(Venugopalan et al., 2014)(Kannan and Venugopalan, 2018)(Basha, Ganapathy and Venugopalan, 2018)Studies assessing the parent's ability to care for child's oral health reveal that parents do not have enough time, lack of knowledge in brushing, job/employment stress, and last but not the least, due to nuclear families and working parents many parents do not raise their children themselves and leave them at day-care centers or crèches.(Ashkanani and Al-Sane, 2013).

Figure 12: Bar graph represents the association between gender and consumption of fluoridated water. $X$ axis represents genders and the $\mathrm{Y}$-axis represents the number of participants who responded Whether consuming or not. Chi-square test was done and the association found to be statistically significant. Pearson's chi-square test showing $\mathrm{p}=\mathbf{0 . 0 0 5} .(<0.05)$ hence statistically significant, proving males have consumed more fluoridated water than females. Blue represents yes, red represents no.

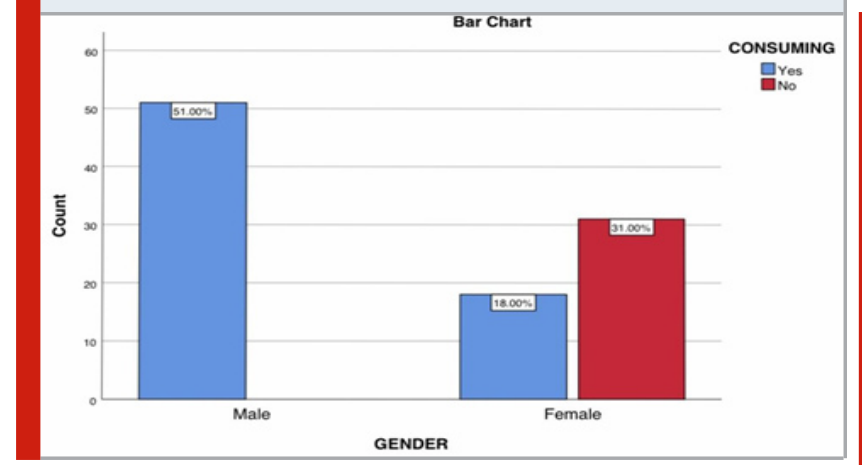

Figure 13: Bar graph represents the association between gender and consuming junk foods that can cause decaying of teeth. The $\mathrm{X}$-axis represents genders and the $\mathrm{Y}$-axis represents the number of participants who responded whether junk foods cause decaying of tooth or not. Chi-square test was done and the association found to be statistically significant. Pearson's chi-square test showing $\mathrm{p}=0.01 .(<0.05)$ hence statistically significant, proving males have better knowledge than females. Blue represents yes, red represents no.

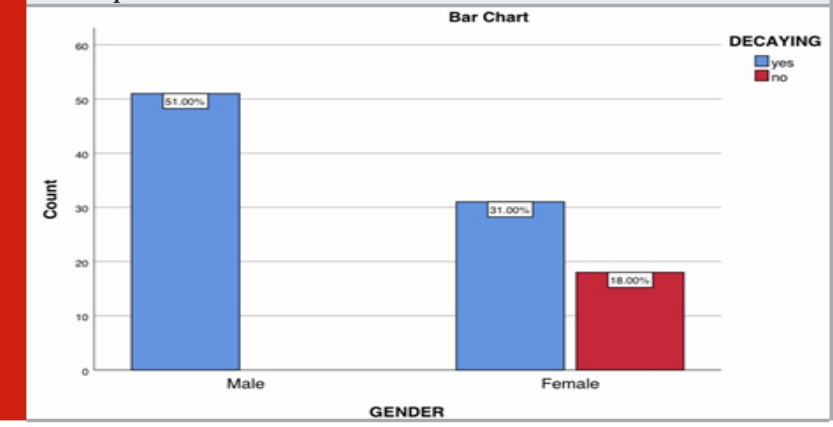

Several studies have found that good knowledge and attitude toward oral health does not necessarily produce good practices. (Alkhtib and Morawala, 2018)From this study, it is clear that awareness regarding bad practices is abundant which is indicated by the low prevalence, i.e. $18.5 \%$ approximately. This reveals an important take home message for us dentists that parents need to be trained and motivated to carry out oral hygiene practices in a proper way and efficiently. In addition, knowledge regarding the use of fluoridated toothpaste (level of evidence for the use of fluoridated toothpaste is $1++$ to $1+$ ) and whether deciduous teeth need treatment appeared to below, i.e., 54\% and 62.5\%, respectively.

In addition, a general low score was found in the knowledge, attitude, and good practices in infant oral health care such as timing for a first dental visit, the ideal time to start the use of fluoridated toothpaste, need to restore deciduous teeth, ill-effects of the night time, frequent and prolonged breast/bottle feeding, harm caused by swallowing of toothpaste.(Alkhubaizi et al., 2018; Mamat, 2018) The role of bacteria in the causation of dental caries was not acknowledged by the majority of the parents which was reflected by the prevalent practice of sharing utensils and biting food into small pieces before feeding in this study. This is in accordance with studies by Mani et al. and (Naidu, Nunn and Irwin, 2015).

Figure 14: Bar graph represents the association between gender and awareness of treatment for dental caries.X axis represents genders and the $\mathrm{Y}$-axis represents the number of participants who responded aware and unaware. Chi-square test was done and the association found to be statistically significant. Pearson's chi-square test showing $\mathrm{p}=\mathbf{0 . 0 0 6}$. $(>0.05)$ hence statistically significant, proving males have better awareness than females. Blue represents yes, red represents no.

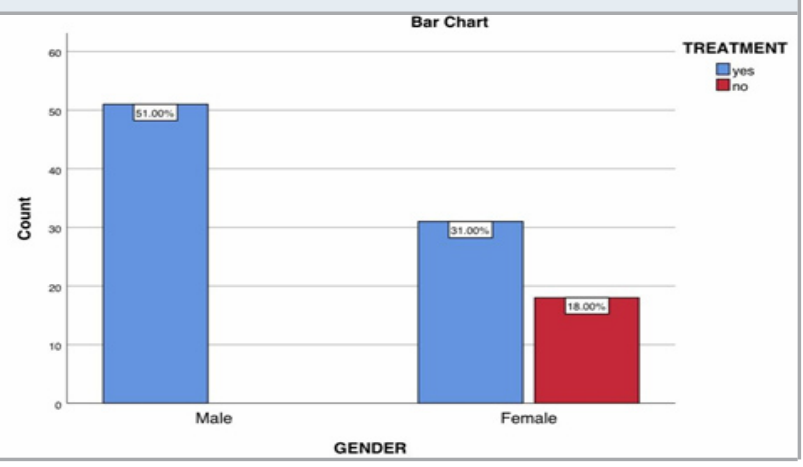

The focus should be on parents/carers to encourage to limit their practice of sharing utensils and biting food invited to carry out oral hygiene practices in proper way carers and children should be advised that foods and drinks containing sugar substitutes are available, but should be consumed in moderation. Sugar-free medicines should be used when available. Parents/carers should be encouraged to brush their child's age as soon as the first tooth appears, using a soft toothbrush and water only. Children who use a baby bottle should be advised never to put sweet drinks, including fruit juice, into the bottle and breast-feeding should not be practiced at the will of the child. Parents/carers should be advised not to let their child sleep or nap with a baby bottle or being breast-fed. (Ramesh Nagarajappa et al., 2013; R. Nagarajappa et al., 2013)Other studies also revealed that parents are aware of the fact that milk teeth are as important as permanent teeth and also affect the general health of the child. In spite of these facts being known to parents, their inability to take proper oral health care is indeed surprising, and the hurdles in practicing oral health practices along 
with other reasons behind this situation can be further explored using qualitative study.

Limitation of the Study: The limitations of this study were that it was carried out in one institution only by convenience sampling or nonprobability sampling with a small sample size.

\section{CONCLUSION}

There was a general lack of knowledge on methods of oral health maintenance even though the participants acknowledged that oral health was vital to general wellbeing. Routine dental camps should be conducted with clinicians demonstrating oral hygiene practices and performing check-ups.

\section{ACKNOWLEDGEMENTS}

The authors like to thank the editors and authors of the journal, which was the source for the scientific compilation of this review article.

Authors Contribution: The authors have carried out the study by collecting data from search engines and drafted the manuscript after performing the necessary statistical analysis. They have aided in the conception of the topic, have participated in the study design, statistical analysis and have supervised in preparation of the manuscript. The authors have participated in the study design and have coordinated in developing the manuscript. All authors have discussed the study details among themselves and contribute to the final manuscript.

Conflict of Interest: Authors declare no potential Conflict of interest.

\section{REFERENCES}

Ajay, R. et al. (2017) 'Effect of surface modifications on the retention of cement-retained implant crowns under fatigue loads: An In vitro study', Journal of Pharmacy And Bioallied Sciences, p. 154. doi: 10.4103/ jpbs.jpbs_146_17.

Alkhtib, A. and Morawala, A. (2018) 'Knowledge, Attitudes, and Practices of Mothers of Preschool Children About Oral Health in Qatar: A Cross-Sectional Survey', Dentistry Journal, p. 51. doi: 10.3390/dj6040051.

Alkhubaizi, Q. et al. (2018) 'Oral health practices and knowledge among parents and hired caregivers', European Archives of Paediatric Dentistry, pp. 403-410. doi: 10.1007/s40368-018-0372-6.

Almeida, A. G. et al. (2000) 'Future caries susceptibility in children with early childhood caries following treatment under general anesthesia', Pediatric dentistry, 22(4), pp. 302-306. Available at: https://www.ncbi.nlm. nih.gov/pubmed/10969437.

American Academy of Pediatric Dentistry, American Academy of Pediatrics and American Academy of Pediatric Dentistry Council on Clinical Affairs (2005)
'Policy on early childhood caries (ECC): classifications, consequences, and preventive strategies', Pediatric dentistry, 27(7 Suppl), pp. 31-33. Available at: https:// www.ncbi.nlm.nih.gov/pubmed/16541878.

Andreasen, J. 0., Andreasen, F. M. and Andersson, L. (2018) Textbook and Color Atlas of Traumatic Injuries to the Teeth. John Wiley \&t Sons. Available at: https://books. google.com/books/about/Textbook_and_Color_Atlas_ of_Traumatic_In.html?hl=etid=60NwDwAAQBAJ.

Ariga, P. et al. (2018) 'Determination of Correlation of Width of Maxillary Anterior Teeth using Extraoral and Intraoral Factors in Indian Population: A Systematic Review', World Journal of Dentistry, pp. 68-75. doi: 10.5005/jp-journals-10015-1509.

Ashkanani, F. and Al-Sane, M. (2013) 'Knowledge, attitudes and practices of caregivers in relation to oral health of preschool children', Medical principles and practice: international journal of the Kuwait University, Health Science Centre, 22(2), pp. 167-172. doi: 10.1159/000341764.

Ashok, V. et al. (2014) 'Lip Bumper Prosthesis for an Acromegaly Patient: A Clinical Report', The Journal of Indian Prosthodontic Society, pp. 279-282. doi: 10.1007/ s13191-013-0339-6.

Ashok, V. and Suvitha, S. (2016) 'Awareness of all ceramic restoration in rural population', Research Journal of Pharmacy and Technology, p. 1691. doi: 10.5958/0974-360x.2016.00340.1.

Basha, F. Y. S., Ganapathy, D. and Venugopalan, S. (2018) 'Oral Hygiene Status among Pregnant Women', Research Journal of Pharmacy and Technology, p. 3099. doi: 10.5958/0974-360x.2018.00569.3.

Bedi, R., Lewsey, J. and Gilthorpe, M. (2000) 'Changes in oral health over ten years amongst UK children aged 4-5 years living in a deprived multiethnic area', British Dental Journal, pp. 88-92. doi: 10.1038/ sj.bdj.4800692a.

Castilho, A. R. F. de et al. (2013) 'Influence of family environment on children's oral health: a systematic review', Jornal de Pediatria, pp. 116-123. doi: 10.1016/j. jped.2013.03.014.

Duraisamy, R. et al. (2019) 'Compatibility of Nonoriginal Abutments With Implants: Evaluation of Microgap at the Implant-Abutment Interface, With Original and Nonoriginal Abutments', Implant dentistry, 28(3), pp. 289-295. doi: 10.1097/ID.0000000000000885.

Ganapathy, D. et al. (2016) 'Effect of Resin Bonded Luting Agents Influencing Marginal Discrepancy in All Ceramic Complete Veneer Crowns', Journal of clinical and diagnostic research: JCDR, 10(12), pp. ZC67-ZC70. doi: 10.7860/JCDR/2016/21447.9028.

Ganapathy, D. M., Kannan, A. and Venugopalan, S. (2017) 'Effect of Coated Surfaces influencing Screw Loosening in Implants: A Systematic Review and Metaanalysis', World Journal of Dentistry, pp. 496-502. doi: 
10.5005/jp-journals-10015-1493.

Halawany, H. S. et al. (2018) 'Effectiveness of oral health education intervention among female primary school children in Riyadh, Saudi Arabia', The Saudi Dental Journal, pp. 190-196. doi: 10.1016/j. sdentj.2018.04.001.

Jain, A., Ranganathan, H. and Ganapathy, D. (2017) 'Cervical and incisal marginal discrepancy in ceramic laminate veneering materials: A SEM analysis', Contemporary Clinical Dentistry, p. 272. doi: 10.4103/ ccd.ccd_156_17.

Jyothi, S. et al. (2017) 'Periodontal Health Status of Three Different Groups Wearing Temporary Partial Denture', Research Journal of Pharmacy and Technology, p. 4339. doi: 10.5958/0974-360x.2017.00795.8.

Kannan, A. and Venugopalan, S. (2018) 'A systematic review on the effect of use of impregnated retraction cords on gingiva', Research Journal of Pharmacy and Technology, p. 2121. doi: 10.5958/0974360x.2018.00393.1.

Mamat, Z. (2018) 'Parental Knowledge and Practices on Preschool Children Oral Healthcare in Nibong Tebal Penang, Malaysia', J0J Nursing \& Health Care. doi: 10.19080/jojnhc.2018.07.555716.

Nagarajappa, R. et al. (2013) 'Comparative assessment of dentition status among poliomyelitis children in Udaipur, India', Special Care in Dentistry, pp. 85-90. doi: 10.1111/j.1754-4505.2012.00298.x.

Nagarajappa, R. et al. (2013) 'Oral health promoting factors: a preliminary survey on knowledge, attitude and practise among caregivers in Udaipur, India', European Archives of Paediatric Dentistry, pp. 105-112. doi: 10.1007/s40368-013-0020-0.

Naidu, R., Nunn, J. and Irwin, J. D. (2015) 'The effect of motivational interviewing on oral healthcare knowledge, attitudes and behaviour of parents and caregivers of preschool children: an exploratory cluster randomised controlled study', BMC Oral Health. doi: 10.1186/s12903-015-0068-9.

Sankeshwari, R. M. et al. (2012) 'Feeding habits and oral hygiene practices as determinants of early childhood caries in 3- to 5-year-old children of Belgaum City, India', Oral health \&t preventive dentistry, 10(3), pp. 283-290. Available at: https://www.ncbi.nlm.nih.gov/ pubmed/23094272.

Selvan, S. R. and Ganapathy, D. (2016) 'Efficacy of fifth generation cephalosporins against methicillin-resistant Staphylococcus aureus-A review', Research Journal of Pharmacy and Technology, p. 1815. doi: 10.5958/0974360x.2016.00369.3.

Sen, N. et al. (2017) 'Oral Health-related Knowledge, Attitude, and Practices among Patients attending the Department of Public Health Dentistry of a Dental Hospital in Udaipur, India', International Journal of Preventive and Clinical Dental Research, pp. 43-49. doi: 10.5005/jp-journals-10052-0079.

Sheiham, A. (2005) 'Oral health, general health and quality of life', Bulletin of the World Health Organization, 83(9), p. 644. doi: /S0042-96862005000900004.

Silk, H. et al. (2012) 'Smiles for Life National Oral Health Curriculum: Module 5. Oral Health in Pregnancy', MedEdPORTAL. doi: 10.15766/mep_2374-8265.9259.

Subasree, S., Murthykumar, K. and Dhanraj (2016) 'Effect of Aloe Vera in Oral Health-A Review', Research Journal of Pharmacy and Technology, p. 609. doi: 10.5958/0974-360x.2016.00116.5.

Tate, A. R. et al. (2002) 'Failure rates of restorative procedures following dental rehabilitation under general anesthesia', Pediatric dentistry, 24(1), pp. 69-71. Available at: https://www.ncbi.nlm.nih.gov/ pubmed/11874065.

Venugopalan, S. et al. (2014) 'Magnetically retained silicone facial prosthesis', Nigerian journal of clinical practice, 17(2), pp. 260-264. doi: 10.4103/11193077.127575.

Vijayalakshmi, B. and Ganapathy, D. (2016) 'Medical management of cellulitis', Research Journal of Pharmacy and Technology, p. 2067. doi: 10.5958/0974360x.2016.00422.4.

Williams, N. J., Whittle, J. G. and Gatrell, A. C. (2002) 'The relationship between socio-demographic characteristics and dental health knowledge and attitudes of parents with young children', British Dental Journal, pp. 651-654. doi: 10.1038/sj.bdj.4801652.

Wright, G. Z. and Kennedy, D. B. (1978) 'Space control in the primary and mixed dentitions', Dental clinics of North America, 22(4), pp. 579-601. Available at: https:// www.ncbi.nlm.nih.gov/pubmed/279479. 